\title{
Managing the empathic culture of client- oriented personnel in the system of human resource development in the Russian regions
}

\author{
Yulia Salamatina* \\ Ural State University of Economics, Department of Management and Entrepreneurship, 620144 \\ Ekaterinburg, Russia
}

\begin{abstract}
The article is devoted to a study on the management of an important professional and personal quality of any employee of a customer-oriented company - empathic culture. The relevance of this research is due to the low level of human resource development in Russian regions. Having conducted an in-depth analysis on the research problem, the author has come to the conclusion that it is the empathic culture of personnel that has a huge impact on efficiency and profitability of any Russian client-oriented company. The author identified the main components of empathic culture of front liners and selected methods to determine the level of formation and development of each of the components. Based on the data following this research, which was conducted on the basis of three client-oriented organisations, the author proposed the most effective ways to manage the empathic culture of staff in order to successfully operate the companies.
\end{abstract}

\section{Introduction}

The modern Russian economy has a regionally segmented labour market. It is characterized by incomplete formation of an efficient sectoral employment structure. The differentiation of regional labour market indicators is identified by different starting terms for its reform, differences in the nature of regional regulatory measures and the level of development of social partnership institutions. Being favored on the labor market the regions have a high level of institutional development and an efficient employment structure that is determined largely by the coherence and synchronization of the mechanisms of adjacent markets.

In today's dynamic information technology environment, there has been a restructuring of the workforce. Coordination mechanisms of resource influence and social partnership, methods of legal, financial and organisational regulation are coming to the fore. The peculiarity of using the institutional-competent approach in public management of human resources is to create the necessary qualitative characteristics of human resources by improving the process of formation and implementation of professional competences [1]. In other words, the problem of organisational culture development has firmly established itself as an undeniable social phenomenon and a key factor in the success of a client-oriented

\footnotetext{
*Corresponding author: kpn1308@mail.ru
} 
organisation. The importance of organisational culture is related to the specifics of a customer-centric company. The culture of the organisation effects on employee morale and their interaction with customers. It is, in turn, affects the effectiveness of the company. As a result, the success of the employees of a customer-oriented company depends not only on the qualification of the personnel, on the quality of customer service, the organisation of certain processes within the company that are associated with the production and delivery of a product or service. It also depends on the personal qualities of employees, such as: the ability to interact competently with customers and the public, the ability to understand the interlocutor through non-verbal communication, anticipate reactions and behaviour of customers analyse their own behaviour. These skills are associated with an empathic culture.

Thus, service quality should be studied in this relationship with the culture of the organisation and the empathic culture of employees $[2 ; 3 ; 4]$. Based on the above, it can be stated that considering empathic culture as an element of organisational culture is crucial for the success and improvement of the customer relationship process.

Therefore, the purpose of this paper is to identify ways to manage staff empathic culture as part of organisational culture in customer-centric companies and to determine the level of empathic culture development in employees, who is a key factor of organisational success.

\section{Materials and Methods}

The empathic culture of staff itself is not a subject of separate research in management. Only empathy and reflexivity have been the subject of a number of studies, but these qualities have been studied in the context of corporate or organizational culture or as a professional quality of senior managers[5].

According to the previous research on empathic culture in customer-centric company, this quality is a professional-personal one included in the structure of organizational culture as well as customer centricity, employee engagement and loyalty[6].

Empathy culture in pedagogy is understood as a type of professional culture of a teacher in which empathy, empathy and tolerance are the main values in the implementation of professional activities[7]. This definition corresponds to and can be applied to frontline staff, but it is not a type of professional culture, but a type of corporate-organisational culture.

As for the main components of empathic culture, based on the identified types of empathy in general (emotional, cognitive and predicative)[7], the following components of frontline staff empathic culture can be distinguished: cognitive, emotional-activity, motivation value-based.

Below is the characteristic of each component, taking into account the activity of clientoriented personnel.

The cognitive component includes a body of knowledge about empathic interaction between persons. It allows us to analyse the reactions and emotions of the interlocutor and on this basis create tactics to manage the situation of communication. In management, the cognitive type of empathy is considered in relation to the heads of organizations and management bodies.

Emotional-activity component is manifested in the ability to respond emotionally to the client's experiences, to implement adequate ways of behaviour in accordance with the emotional state of the subjects of interaction. The main function of this component of empathic culture is to solve communicative tasks, establish trusting contact with the client, relieve emotional tension, and build a strategy for managing the communication situation. This component of empathic culture requires life experience and a formed first component. 
Motivation-value component reflects the orientation of the employee's personality, manifested in the acceptance of empathy as a professional value, in the aspiration to improve empathic attitude in professional activity while working with clients. We allocated this component as we investigate empathy culture, and under culture, we will understand the system of norms of activity created based on the moral, value and intellectual criteria defining a level of development of the person [8].

Thus, after conducting an in-depth theoretical analysis of the research problem, we conclude that empathic culture is a component of organisational culture, in which loyalty, involvement and customer focus of the employee are the main values of professional activity.

In order to identify the best ways to manage the development of employees' empathic culture, it is necessary to determine the level of development of each component of this quality. The following methods selected were for this purpose:

- psychological test to diagnose professional and personal qualities (in our case to diagnose the level of empathic culture development in general);

- Analysis of customer service quality questionnaires (determining the level of cognitive component of empathic culture);

- methods of social network analysis (SNA). The essence of the method is the following: after collecting information about different aspects of work interactions and employees' contacts with each other, data obtained is processed and analysed at the same time. This method we used together with T. Leary's diagnostic method of interpersonal relations. T. Leary's diagnostic technique reveals the predominant type of attitude towards people in self-assessment and mutual evaluation according to the factors "dominancesubordination" and "friendliness-aggressiveness (hostility)";

- M. Rokich's method "Value orientations" to determine the level of motivational-value component of empathic culture of an employee. This technique provides an opportunity to identify value preferences of staff in performing their professional duties. In addition, the author's questionnaire used for assessing the behavioural manifestation of loyalty and involvement, which is part of the motivational and value component.

\section{Results and discussion}

Three organisations chosen were as the basis for this study: an educational institution (college), a social service organisation (job centre) and a service company (restaurant). The choice of these organisations based on such factors, as all three organisations are clientoriented, and at the same time the clients of these companies, as well as the employees, are people of different ages, social status and living standards. On this basis, we believe that the data obtained on the indicators of the development of empathic culture components are the most reliable.

The total number of participants was initially 135 people, but after the questionnaire was distributed, it became 125. As a result, the total number of questionnaires was 125: 45 people completed the questionnaire at the college, 41- at the job centre, and 39 - at the restaurant staff. It should be noted that the study did not include the entire staff of the organizations represented, but only front-line workers: at the college, these were primarily teachers; at the employment centre, these were specialists who interacted directly with clients and provided advice and job searches; and at the restaurant, these were waiters, barmen and receptionists. The age category of the participants is presented in the Table 1. 
Table 1. Age range of survey participants for each organisation

\begin{tabular}{|l|l|}
\hline Company & Age category \\
\hline College & $25-48$ y.o. \\
\hline Job Centre & $37-58$ y.o. \\
\hline Restaurant & $19-31$ y.o. \\
\hline
\end{tabular}

In the process of careful analysis of the data obtained after applying diagnostic techniques to determine the level of development of each component of organisational culture, the results obtained (Table 2). The table presents the results for each component based on the overall results of the specific company that participated in the study. It should be noted here that the age criterion plays a key role in the development of some components of empathic culture.

In addition, the following criterion-level characteristic we used for the distribution of participants according to the level of development for each component of empathic culture:

Reproductive level, productive level and heuristic level.

The following evaluation procedure used is to quantify the degree of manifestation of the selected indicators.

The basis for quantitative assessment of empathic culture is the method of deriving the average score based on the following steps:

- high level of manifestation of each component was evaluated with 3 points;

- medium level of manifestation - 2 points;

- low level - 1 point;

- all the obtained scores are summed up (sum of scores on the indicators of cognitive, emotional-activity, motivation-value components) and divided by 3 (according to the number of components that constitute empathic culture):

Table 2. Level results of empathic culture for each component

\begin{tabular}{|c|c|c|c|c|c|c|c|c|}
\hline \multirow{3}{*}{ Company } & \multirow{3}{*}{$\begin{array}{l}\text { Number of } \\
\text { participants }\end{array}$} & \multirow{3}{*}{$\begin{array}{l}\text { Component of the } \\
\text { empathic culture }\end{array}$} & \multicolumn{6}{|c|}{ Levels } \\
\hline & & & \multicolumn{2}{|c|}{ reproductive } & \multicolumn{2}{|c|}{ productive } & \multicolumn{2}{|c|}{ heuristic } \\
\hline & & & Abs. & $\%$ & Abs. & $\%$ & Abs. & $\%$ \\
\hline \multirow{4}{*}{ College } & \multirow{4}{*}{45} & cognitive component & 23 & 62,2 & 13 & 35,1 & 1 & 2,7 \\
\hline & & $\begin{array}{l}\text { emotional-activity } \\
\text { component }\end{array}$ & 24 & 64,9 & 13 & 35,1 & 0 & 0,0 \\
\hline & & $\begin{array}{l}\text { motivation-value } \\
\text { component }\end{array}$ & 18 & 48,6 & 19 & 51,4 & 0 & 0,0 \\
\hline & & Group assessment & 65 & 58,6 & 45 & 40,5 & 1 & 0,9 \\
\hline \multirow{4}{*}{ Job centre } & \multirow{4}{*}{41} & cognitive component & 24 & 70,6 & 9 & 26,5 & 1 & 2,9 \\
\hline & & $\begin{array}{l}\text { emotional-activity } \\
\text { component }\end{array}$ & 16 & 47,1 & 18 & 52,9 & 0 & 0,0 \\
\hline & & Motivational value & 18 & 52,9 & 16 & 47,1 & 0 & 0,0 \\
\hline & & Group assessment & 58 & 56,9 & 43 & 42,2 & 1 & 0,9 \\
\hline \multirow{4}{*}{ Restaurant } & \multirow{4}{*}{39} & cognitive component & 24 & 61,5 & 14 & 35,9 & 1 & 2,6 \\
\hline & & $\begin{array}{l}\text { emotional-activity } \\
\text { component }\end{array}$ & 25 & 64,1 & 13 & 33,3 & 1 & 2,6 \\
\hline & & $\begin{array}{l}\text { motivation-value } \\
\text { component }\end{array}$ & 19 & 48,7 & 19 & 48,7 & 1 & 2,6 \\
\hline & & Group assessment & 68 & 58,1 & 46 & 39,3 & 3 & 2,6 \\
\hline
\end{tabular}

As can be seen from the table, a total of 125 people were surveyed, the results of which showed

- insufficient level of empathic culture formation;

- similarity of the results in the level of empathic culture of the staff in general.

In addition, based on the data obtained to identify the level of formation and manifestation of components of empathic culture of client-oriented personnel, the lowest 
indicators are in the Employment Centre, followed by the college and the best in the restaurant. As noted above, the age of the participants played a major role in these indicators. Restaurant staff had the highest score. Despite the fact that the restaurant staff were mostly people without a professional degree (students), it was found that these young people are oriented in the long term towards quick learning and development of professional-personal qualities, which is empathic culture.

Based on the research conducted to determine the level of formation of empathy culture components for the staff of client-oriented organizations in the Urals region, managers were proposed the following ways of improving and developing the management of this quality

- On the basis of observation of employees' activities, as well as through personal conversations, to identify motives for behaviour and its causes;

- Improve not only the professionalism of employees but also their personal qualities through various trainings and seminars. Personal qualities can have a direct impact on the profitability of a company;

- Involve employees in the life of the company through their own involvement and loyalty;

- review the working conditions of employees and take measures to improve them (reducing their workload, improving the reward system, allocating people according to their own preferences, etc.);

Receive feedback from the team (by gradually engaging people in a two-way dialogue, useful information can be obtained. Customer-focused companies should make it a policy to discuss innovations before they are introduced into the process. Employees will feel valued and become more involved in the company. In addition, most importantly: when you receive feedback from your subordinates, you need to respond to it.

\section{Conclusion}

In todays evolving society, when often the only difference between the goods and services of companies that the customer is able to see is the quality of their provision and service. It is the attitude, the new approaches to customers, that ultimately makes it possible to increase the loyalty of buyers of services and goods towards the organisations that provide them. Experts in marketing and sales point out that customer focus is one of the most significant factors in the growth of enterprises, an effective sales tool that ensures their sustainable competitive advantage. Thus, the development of such a personal quality as empathic culture in customer-oriented personnel in any organisation is a very topical issue and research problem, as it is often the interpersonal interaction of customer-oriented personnel with customers that determines the further development of the company.

The results of this research are not final. Moreover, for obtaining additional results that confirm the conclusions presented in this article or refute them, we consider advisably to conduct research in the following directions: study of factors (internal and external) influencing the level of development of organizational culture of client-oriented company, study of organizational culture in the sphere of social services, educational activities, catering in order to build systems

\section{References}

1. A. Kokovikhin, Manager, 11(5) (2020)

2. J. Dunnet, The Business Review, 7(1) (2007)

3. A.C Hax, N.S. Majluf, The Strategy Concept and Process: A Pragmatic Approach (1991) 
4. Mamon, Przemyslaw Organizational Culture, https://www.researchgate.net/ (2020)

5. N.I. Basmanova, A.O. Yatsuk, Scientific Notes of the Russian State Social University, 18, 2(151) (2019)

6. Y.V. Salamatina, Regional Problems of Economic Transformation, 10(120) (2020)

7. Y.V. Salamatina, Science for Education Today, 9(4) (2019)

8. N.V. Kurilovich, Proceedings of Southwestern State University, 2(35) (2011) 